Sierra Leone Journal of Biomedical Research

Vol. 1 (1) pp. 28-32, August, 2009

Original Paper

\title{
Prevalence of Intestinal Helminthes among Children in Selected Communities in Monrovia, Liberia
}

\author{
Sahr Foday ${ }^{1^{*}}$, Jones Joel ${ }^{2}$, Barh Sam $B^{2}$ and Gbakima Aiah $A^{1}$ \\ ${ }^{1}$ Department of Microbiology, College of Medicine and Allied Health Sciences, University of Sierra Leone, \\ ${ }^{2} \mathrm{AM}$ Dogloitti College of Medicine, University of Liberia
}

\begin{abstract}
The present study was carried out among children below 15 years in 10 communities in Monrovia. Out of the 646 children recruited in the study, $216(33.4 \%)$ were positive for at least one intestinal helminth parasite. Children between $11-15$ years had the highest prevalence of intestinal helminthes. Ascaris lumbricoides was the most common intestinal helminth parasite encountered $(79.6 \%)$, followed by Trichuris trichura (19.0\%). Strongyloides stercoralis and Enterobius vermicularis were the least prevalent helminth parasites encountered among the study population ( $1 \%$ each). The population in these communities depended largely on poorly built latrines and buckets for faecal disposal although some (49\%) used flush toilets despite their being in poor conditions. Only 23.45 of the 646 children surveyed used pipe borne water for drinking and other domestic purposes. The high prevalence rates of helminth infection obtained could be due to persistent infection and re-infection of the study population as a result of the constant seeding of the soil with parasite eggs and larvae in these communities.
\end{abstract}

Keywords: Prevalence, Intestinal helminth, Children, Liberia

Received 9 February 2009/ Accepted 24 June 2009

\section{INTRODUCTION}

Worm infestations are a common childhood condition in most developing condition in most developing countries (Mwanthi et al., 2008). Several infections have been identified as an important public health problem (Anah et al., 2008) although most infected persons are usually asymptomatic. In children especially those below 15 years, high worm burden is associated with symptoms including anaemia, anorexia and weight loss (Bowley et al., 2004; Goundasamy and Thompson, 2004). Complications that have been reported with heavy infections include intestinal and duct obstruction that may require surgery (Surendran and Paulose, 1988). The only reported prevalence study on Liberia was by Adongakulu and Reken (1982). The workers reported $21 \%$ prevalence rate of intestinal helminths among school-aged children in Monrovia, with Ascaris lumbricoides being the most prevalent.

The eight year civil crisis which forced large proportion of the Liberian population to live in poor socio-economic conditions, created many suitable environments for the effective transmission of these helminth parasites. Children are especially predisposed to persistent infections and consequent malnutrition that follow chronic infections. The present study aims to determine the prevalence and distribution of various intestinal helminths among children in ten (10) selected communities in Monrovia and correlate the findings with the environmental and sanitary conditions of the communities. 


\section{MATERIALS AND METHODS}

\section{Study Area and Population}

The study was conducted in ten (10) communities $\left(12^{\text {th }}\right.$ Street, Gage Town, Togba Town, Mewkru Town, Stephen Tolbert Estate, Duport road, Bardnseville, Mamba Point, Lakpazae, West Point) in Monrovia. These ten communities are the peri-urban settlements around Monrovia. Before the civil crisis, all these communities had pipe borne water and standard faecal disposal facilities. The populations in these communities now depend largely on poorly built latrines for adult, whilst children defecate indiscriminately around houses. Some unprotected wells for drinking and other domestic purposes are mainly used in all ten communities.

\section{Collection and Examination of Stool Samples}

The study was approved by the Ethics Committee of the Ministry of Health of Liberia and verbal informed consent was obtained from the parents/ guardians of children participating in the study. All children below 15 years in each of the communities were recruited into the study. Stool cups with tight fitting covers containing $1.0 \mathrm{ml}$ of $0.9 \%$ normal saline were distributed in each community every morning and collected late in the afternoon to be transported to the Central Laboratory at the JFK Medical Centre. In the laboratory, all samples were first examined macroscopically for consistency and evidence of any blood or mucus. Samples were then centrifuged and supernatant decanted. Two wet smears of each specimen were prepared on glass slides and examined under $x 40$ objective of a light microscope only for the presence of ova or larvae of intestinal helminths.

\section{Environmental Health}

A standard pre-tested questionnaire was administered to the parent/guardian of each subject recruited in the study to highlight the type of faecal disposal and domestic water facilities available.

\section{RESULTS}

\section{Prevalence of Intestinal Helminth Infections}

Of the 646 children recruited in this study, 303 $(47 \%)$ were males and $343(53 \%)$ females. Two hundred and seven (33.4\%) of the stools examined were positive for at least one intestinal helminth parasite or larva. Newkru town and West Point were the communities with the highest prevalence rate of $48.7 \%$ and $50 \%$ respectively (Table 1), Bardnesville community had the lowest prevalence rate of $14.0 \%$. With the exception of Gage town, more males were infected with intestinal helminth parasites than females. In some communities, it was interesting to note that more than half of the males recruited were infected with at least one intestinal helminth. In Togba town, $16(80 \%)$ of the 20 males recruited were positive for intestinal helminths. No females were found to be positive for intestinal helminths at Bardnesville.

\section{Age Specific Prevalence of Intestinal Helminths}

Table 2 shows the age specific prevalence rates of intestinal helminths among the study population. Of the 282 children aged $1-5$ years, $21.3 \%$, were positive of at least one intestinal helminth parasite. $30.6 \%$ of the children aged $6-$ 10 years were positive for intestinal helminths. Children in the $11-15$ years age group had the highest prevalence rate of intestinal helminths with $61.4 \%$ positive for intestinal helminths.

\section{Prevalence of Specific Intestinal Helminth Parasites}

The prevalence of the various intestinal helminth parasites among the 216 positive children is shown in Table 3. Ascaris lumbricoides was found to be the most prevalent as $172(79.6 \%)$ of the 216 children positive for intestinal helminthes were found to be infected with the parasite. The second most prevalent intestinal helminth parasite among the study population was Trichuris trichura as ova of the parasite were found in $41(19.0 \%)$ of the 216 positive children. The prevalence rate of hookworm among the study population was $11.1 \%$ and that of tapeworm was $1.3 \%$. Strongyloides stercoralis and Enterobius vermicularis (Table 3) were the least prevalent helminth parasites with prevalence rate of $1 \%$ each. In analyzing the specific multiple intestinal helminth infections, the combination of Ascaris lumbricoides and Tichuris trichura was the most common (13\%) among the study population. The triad Ascaris lumbricoides, Trichuris trichura and hookworm was encountered in $5.6 \%$ of the positive children. 
Table 1: Prevalence of intestinal helminthes infections among the study population

\begin{tabular}{|c|c|c|c|c|c|c|}
\hline \multirow[t]{2}{*}{ Community } & \multicolumn{2}{|c|}{ Male } & \multicolumn{2}{|c|}{ Female } & \multicolumn{2}{|c|}{ Both sexes } \\
\hline & $\begin{array}{c}\text { No } \\
\text { examined }\end{array}$ & $\begin{array}{c}\text { No (\%) } \\
\text { Positive }\end{array}$ & $\begin{array}{c}\text { No } \\
\text { examined }\end{array}$ & $\begin{array}{c}\text { No }(\%) \\
\text { positive }\end{array}$ & $\begin{array}{c}\text { No } \\
\text { examined }\end{array}$ & $\begin{array}{c}\text { No (\%) } \\
\text { Positive }\end{array}$ \\
\hline $12^{\text {th }}$ Street & 32 & $9(28)$ * & 3 & $7(21.2)^{*}$ & 65 & $16(24.6)$ \\
\hline Gage Town & 36 & $7(19.4)^{*}$ & 22 & $5(22.7)^{*}$ & 58 & $12(20.7)$ \\
\hline Togba Town & 20 & $16(80.0)$ & 43 & $8(18.6)$ & 63 & $24(38.1)$ \\
\hline Mewkru Town & 42 & $25(59.5)$ & 36 & $13(36.1)$ & 78 & $38(48.7)$ \\
\hline $\begin{array}{c}\text { Stephen Tolbert } \\
\text { Estate }\end{array}$ & 29 & $12(41.4)$ & 46 & $5(10.9)$ & 75 & $17(22.7)$ \\
\hline Duport Road & 30 & $16(53.3)$ & 26 & $11(42.3)^{*}$ & 56 & $27(48.2)$ \\
\hline Bardnesville & 19 & 7 (36.3) & 31 & & 50 & $27(14.00$ \\
\hline Mamba Point & 26 & $10(38.5)$ & 29 & $2(6.9)$ & 55 & $12(21.8)$ \\
\hline Lakpazae & 38 & $22(57.9)$ & 44 & $9(20.5)$ & 82 & $31(37.8)$ \\
\hline West Point & 303 & $141(46.5)$ & 343 & 75 (21.9) & 646 & $216(33.4)$ \\
\hline
\end{tabular}

No statistically significant difference between males and females at $p \leq 0.05$

\section{Environmental Health}

Of the 646 children recruited in the survey, 323 $(50 \%)$ used flush toilets despite their being in very poor conditions, $21.4 \%$ used pit latrines, $1 \%$ used bucket latrines, whilst $1.5 \%$ defecated in the open or used the faecal disposal facilities of their neighbors (Table 4). About $28 \%$ of the 323 helminth positive children used flush toilets. Forty-one percent (Table 4) of the 175 children who used bucket latrines had ova or larvae of intestinal helminth parasites whilst $50 \%$ of those 10 who defecated in the open had ova or larva of intestinal helminth parasites in their stool. About three fourth of the children recruited in the survey used water obtained from hand pumps for drinking and other domestic use, whilst $23.4 \%$ used pipe borne water. None of the communities

\section{DISCUSSIONS AND CONCLUSION}

Results of the present study indicate a high prevalence of intestinal helminths among the children recruited. The $33.4 \%$ prevalence rate reported from the present study is greater than the $21 \%$ prevalence rate reported from a previous study in the country (Adunkagulu and Reken, 1982). The increased prevalence rate observed among children in the country could be due to the fact that the eight year civil crisis was depended on natural unprotected streams for domestic needs.

Table 2: Age specific prevalence of intestinal helminth parasites among 646 children examined

\begin{tabular}{l|ll|l}
$\begin{array}{l}\text { Age } \\
\text { Group } \\
\text { (yrs) }\end{array}$ & $\begin{array}{l}\text { No } \\
\text { Examined }\end{array}$ & $\begin{array}{l}\text { No } \\
\text { Positive }\end{array}$ \\
\hline $\mathbf{1 - 5}$ & \multicolumn{3}{|}{ \% Positive } \\
$\mathbf{6 - 1 0}$ & 219 & 60 & $\mathbf{2 1 . 3}$ \\
$11-15$ & 145 & 67 & 30.6 \\
TOTAL & 646 & 89 & 61.4 \\
\cline { 2 - 4 } & & 216 & 33.4 \\
& & &
\end{tabular}

accompanied by destruction of the general infrastructure of the communities including the faecal disposal facilities, hence effecting the transmission of intestinal helminths. difference between prevalence rates of intestinal helminths among those who defecated in the open and those who used flush toilets. Also, a statistically significant difference was observed between the prevalence rate of those who used flush toilets and those who used bucket latrines. 
Table 3: Prevalence of specific Intestinal Helminths

\begin{tabular}{lll}
\hline $\begin{array}{l}\text { Intestinal } \\
\text { Helminth } \\
\text { Parasite }\end{array}$ & No Infected & \% Infected \\
$\begin{array}{l}\text { Ascaris } \\
\text { lumbricoides }\end{array}$ & 172 & 76.6 \\
$\begin{array}{l}\text { Trichuris trichura } \\
\text { Hookworm }\end{array}$ & 41 & 19.0 \\
$\begin{array}{l}\text { Strongyloides } \\
\text { stercoralis }\end{array}$ & 24 & 11.1 \\
$\begin{array}{l}\text { Enterobius } \\
\text { vernicularis }\end{array}$ & 2 & 1.0 \\
Tapeworm & 3 & 1.0 \\
Others & 6 & 1.3 \\
\hline
\end{tabular}

Although a higher prevalence rate of intestinal helminths was observed in children who used pit latrines (34.8\%) compared to those who used flush toilets $(28.2 \%)$, this difference was not observed to be statistically significant (at $p \leq 0.05$ ). Out of the 216 children that had at least one intestinal helminth, $89(61.4 \%)$ were in the 11 15 years age group. The lowest prevalence rate of $21.3 \%$ was found in children in the $1-5$ year age group. The high prevalence of intestinal helminth parasites in children in the $11-15$ years age group is not surprising as children in this age group are almost always with peer groups playing in fields and between houses. Ascaris lumbricoides was the most frequently occurring intestinal helminth $(76.6 \%)$ with Strongyloides stercoralis and Enterobius vernicularis being the leastprevalent.

Table 4: Prevalence of Intestinal Helminth parasite against faecal disposal facility

\begin{tabular}{l|l|l}
$\begin{array}{l}\text { Type of faecal } \\
\text { disposal }\end{array}$ & $\begin{array}{l}\text { No of subjects using } \\
\text { the facility }\end{array}$ & $\begin{array}{l}\text { (\%) positive for Intestinal } \\
\text { Helminth }\end{array}$ \\
\hline Flush toilet & 323 & $\mathbf{9 1 * ( 2 8 . 2 )}$ \\
Pit latrine & 138 & $\mathbf{4 8 ( 3 4 . 8 )}$ \\
Bucket latrine & 175 & $\mathbf{7 2 * ( 4 1 . 1 )}$ \\
Open defecation & 10 & $\mathbf{5 ( 5 0 . 0 )}$ \\
Total & 646 & $\mathbf{2 1 6 ( 3 . 4 )}$
\end{tabular}

Statistically significant difference at $p \leq 0.05$ between children using flush toilets and those using bucket latrines and also between the same subjects using flush latrines and those involved in open defecation.

Ascaris lumbricoides was the most frequently occurring intestinal helminth $(76.6 \%)$ with Strongyloides stercoralis and Enterobius vernicularis being the least prevalent. Hookworm and Trichuris trichura were respectively found in $11.1 \%$ and $19.0 \%$ of the study population. The high prevalence of Ascaris lumbricoides in our study is unlike results from other studies elsewhere that reported hookworm as the most prevalent intestinal helminth (Gbakima and Sahr, 1995; Anah et al., 2008; Mwanthi et al., 2008).

High prevalence of intestinal helminths was found in children who defecated in the open $(50 \% 0$ and those who used buckets $(41.1 \%)$ for faecal disposal. There was indeed a statistically significant The high prevalence rates observed in children defecating in the open and those who used bucket latrines could be as a result of the regular contact with faecal matter, thus effecting faeco-oral transmission of intestinal helminths. It can be concluded from this study that the high prevalence of intestinal helminths is an indication of poor socio-economic status of these communities, especially after the 8 year civil crisis. It is believed that these high prevalence rates will continue in these communities until effective programs are implemented at the community level to change the social habit of the inhabitants in these communities. It is suggested therefore that these programs should embrace the provision of improved methods of faecal and sewage disposal, good water supply, health education and mass chemotherapy for the heavily infected communities in an attempt to prevent chronic infections. 


\section{ACKNOWLEDGEMENT}

The authors thank the staff of the Pathology Laboratory at the JFK Medical Centre in Monrovia and the elders of the ten communities from where children were recruited into the study.

\section{REFERENCES}

Adongakulu B and Reken DE (1982). Prevalence of Intestinal Helminth infections in children presenting at the JFK Medical Centre in Monrovia, Liberia. J Liberian Med Dent Assoc. 1: 17-20

Anah M, Ikpeme OE, Etuk, IS, Yong KE, Ibanga I and Asuquo BE (2008). Worm Infestation and Anaemia among Pre-School Children of Peasant Farmers in Calabar, Nigeria. Niger J. Clin. Pract. 11: 220 - 4

Bowley DMG, Parmer WK and Baffard KD (2004). Burdens of Disease in Southern Africa. Lancet. 363: 1508
Gbakima AA and Sahr F (1995). Intestinal parasitic infections among rural farming communities in Eastern Sierra Leone. Afri J Med Sci. 24: $195-200$.

Govindasamy V and Thompson SR (2004). Worms wanted dead or alive. South Afr Med J. 94: $524-525$

Mwanthi MA, Kinsti MK, Wamae AW, Ndonga M and Migiro PS (2008). Prevalence of Intestinal worm infections among Primary School Children in Nairobi City, Kenya. East. Afr J Public Health. 15: $86-9$

Surendran W. and Paulose MO (1988). Intestinal complications of round worms in Children. $J$ Pediatr Surg. 3: 931 - 935 